\title{
Median clefting of the upper lip associated with cutaneous polyps
}

\author{
W Reardon, B Jones, M Baraitser
}

\begin{abstract}
Details are presented of a patient with median clefting of the upper lip and cutaneous polyps. Four similar published case reports are considered to share the same condition. The spectrum of the disorder encompassed by these five cases is discussed.
\end{abstract}

One of the problems posed by patients with unusual features is to decide whether the patient represents a new disorder or a rare presentation of an already documented condition. Four published cases have been identified describing median clefts of the upper lip in association with skin polyps involving the nose. $^{1-4}$ To these we wish to add a further case.

\section{Case report}

The proband is a boy, born by spontaneous vaginal delivery after a normal pregnancy. He is the second child of non-consanguineous, Nigerian parents. The older sib is normal. Birth weight was $2700 \mathrm{~g}$ at term. At the time of his birth, his mother was aged 24 and his father 23. The family history was negative.

A midline cleft of the upper lip was noted at birth. This was confined to the vermilion and the philtrum was spared. A polypoid mass was noted extending from the right nostril (figure). This mass was attached by a pedicle to the nasal septum. The left nostril was clear. In addition a skin tag was present at the nasal tip, slightly to the right of the midline. A further skin tag was noted at the base of the nose to the right of the midline. This was associated with a blind ending sinus

\section{Department of Clinical Genetics, The Hospitals for Sick Children, Great Ormond Street, London WC1N 3JH. W Reardon, $M$ Baraitser}

Department of Plastic Surgery, The Hospitals for Sick Children, Great Ormond Street, London WC1N 3JH. B Jones

Correspondence to Dr Reardon.

Received for publication 12 October 1989.

Accepted for publication 1 December 1989. track. No other dysmorphic features were seen and no intraoral pathology was noted. Subsequent growth and development have been normal.

All routine laboratory investigations have been normal. CT scan of the head confirmed normal intracranial structures and no evidence of intracranial extension of the sinus track. MRI scan of the spinal cord was normal.

\section{Discussion}

According to the classification of Millard and Williams ${ }^{5}$ any congenital cleft through the centre of the upper lip constitutes a median cleft of the lip. Three types of median clefts involving the upper lip have been described. ${ }^{6}$ (1) A notch confined to the vermilion. (2) The cleft extends to involve the columella. (3) A defect caused by lack of development of the whole median element.

As an isolated finding, median clefting of the upper lip is rare, only eight cases being recorded in a review of 3988 patients. $^{7}$ Syndrome related median clefting of the upper lip may be seen in several conditions. A search conducted in the London Dysmorphology Database for median clefting of the upper lip showed 19 possibilities (table). Many of these conditions, such as lethal short rib syndrome, Ellis-van Creveld, MohrMajewski, orofaciodigital syndrome types 1 and 2, Pallister $W$, polydactyly-short rib type 2 , and polydactyly-cleft lip have skeletal abnormalities and can be excluded in this situation. The same applies to holoprosencephaly and related conditions. Our patient does not have Goldenhar's syndrome, cleft lip and palate with pituitary deficiency, Meckel-like syndrome, or anocerebrodigital syndrome. Neither is there any evidence to support a diagnosis of oculocerebrocutaneous syndrome. The case described by Pai $e t a l^{2}$ is the only condition from which our patient cannot be comfortably excluded.

The present case report is the fifth case where median clefting of the upper lip has been recorded with polypoid skin lesions of the nose. The degree of clefting represented by these cases ranges from notching of the vermilion border, as in the present case and that reported by Nakamura et al, ${ }^{3}$ to more extensive involvement of the columella. ${ }^{2}$ The polypoid masses, single in two of the five cases and 

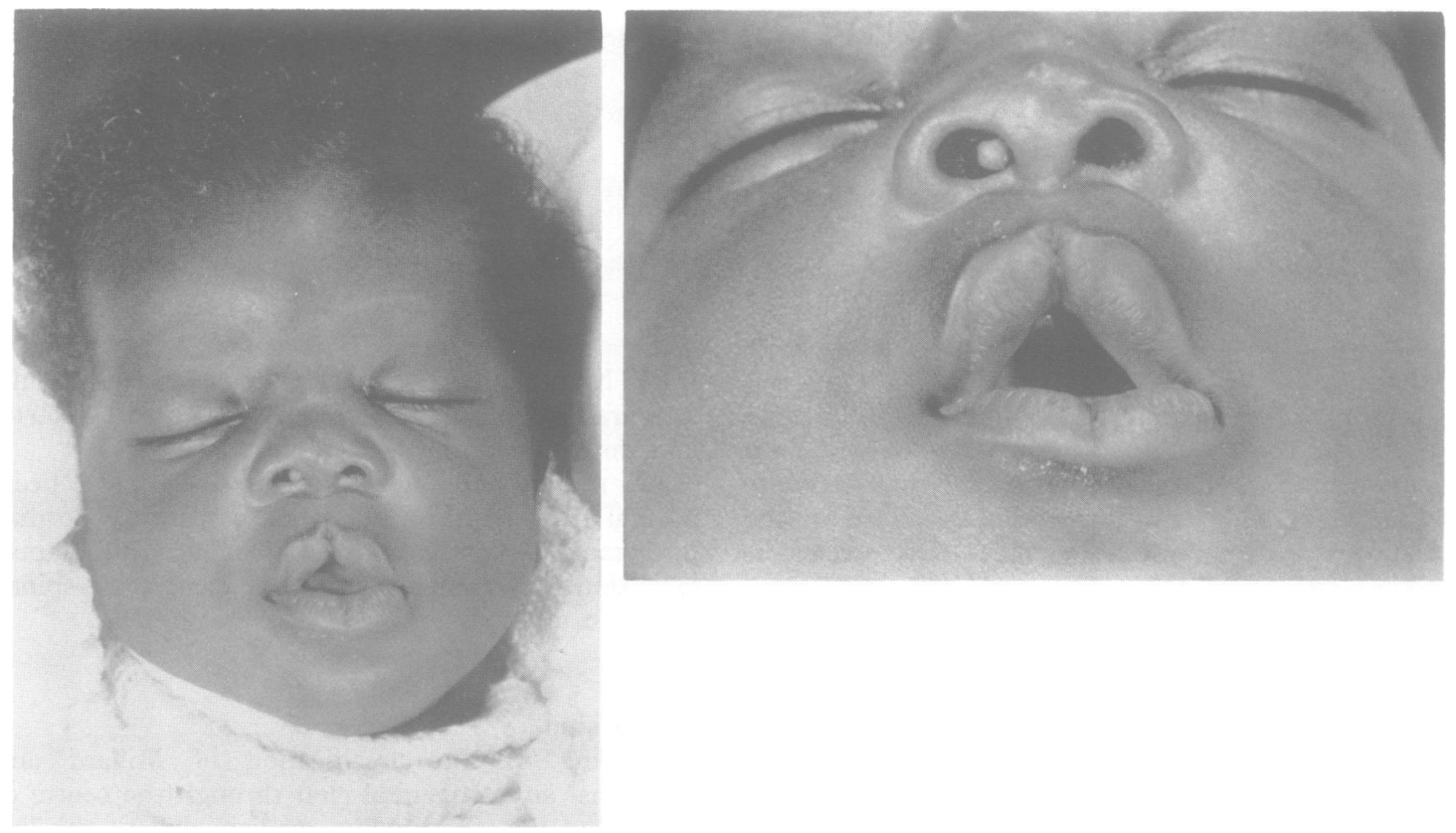

The midline clefting of the upper lip is shown with the nasal polyp and skin tags.

London Dysmorphology Database: syndrome search.

Selection criteria:

Midline cleft upper lip

(1) Beemer (1983) Lethal short rib syndrome

(2) Cleft lip and palate with pituitary deficiency

(3) Clefting-premaxilla agenesis

(4) Edwards (1988) X linked orofaciodigital syndrome

(5) Ellis-van Creveld

(6) Fried (1974) Meckel-like syndrome

(7) Goldenhar (facioauriculovertebral) hemifacial microsomia

(8) Grote (1984) Holoprosencephaly-polydactyly

(9) Holoprosencephaly (familial)

(10) Mohr-Majewski compound

(11) Oculocerebrocutaneous (Delleman)

(12) OFD-1 Orofaciodigital (type 1)

(13) OFD-2 Orofaciodigital type 2 (Mohr)

(14) Pai (1987) Median cleft lip-lipomas-cutaneous polyps

(15) Pallister-Hall anocerebrodigital

(16) Pallister-W Clefting-MR-skeletal defects

(17) Polydactyly-cleft lip

(18) Short rib-polydactyly type 2 (Majewski)

(19) Steinfeld (1982) Holoprosencephaly and limb defects

multiple in the other three cases, have been noted over the nasal septum, in the mouth, or extending from the nostril, but attached to the nasal septum.

In one of these reports ${ }^{2}$ the patient was also found to have a corpus callosum lipoma and an intraspinal mass in the lumbar area. Pathology of this nature is not present in our patient and no mention is made in the other three case reports of central nervous system pathology being specifically excluded.

We suggest that these five patients, with the unusual features of median cleft of the upper lip of variable degree associated with polypoid skin masses, may share the same condition. Further similar case reports will be required if these patients are to be separated as a distinct group from the broader group of patients suffering from median clefts of the upper lip. All cases to date have been single events.

1 Sharma LK. Median cleft of the upper lip. Plast Reconstr Surg 1974;53:155-7.

2 Pai GS, Levkoff AH, Leithiser RE. Median cleft of the upper lip associated with lipomas of the central nervous system and cutaneous polyps. Am 7 Med Genet 1987;26:921-4.

3 Nakamura J, Tomonari H, Goto S. True median cleft of the upper lip associated with three pedunculated club-shaped skin masses. Plast Reconstr Surg 1985;75:727-31.

4 Ponniah RD. Midline cleft lip and associated abnormalities. 7 Laryngol Otol 1977;91:177-81.

5 Millard DR, Williams S. Median lip clefts of the upper lip. Plast Reconstr Surg 1968;42:4-14.

6 Veau V. Bec-de-lievre. Paris: Masson et Cie, 1938

7 Fogh-Andersen P. Rare clefts of the face. Acta Chir Scand 1965;129:275-81. 